\title{
Minimally invasive valve-sparing aortic root reimplantation
}

\author{
Vishal N. Shah ${ }^{1,2}$, Oleg I. Orlov ${ }^{1,2}$, Cinthia Orlov ${ }^{1,2}$, Serge Sicouri ${ }^{1}$, Manabu Takebe ${ }^{2}$, Konstadinos A. \\ Plestis $^{2}$ \\ ${ }^{1}$ Lankenau Institute for Medical Research, ${ }^{2}$ Department of Cardiothoracic Surgery, Lankenau Medical Center, Wynnewood, PA, USA \\ Correspondence to: Dr. Vishal N. Shah, DO. Lankenau Institute for Medical Research, 100 East Lancaster Avenue, Wynnewood, PA 19096, USA. \\ Email: shahv@mlhs.org.
}

\begin{abstract}
Valve-sparing aortic root reimplantation is the technique of choice in appropriately selected patients with aortic root aneurysms. Valve-sparing operations require durable restoration of the structural and functional integrity of the aortic root and valve. These procedures are seldom performed in a minimally invasive fashion. We describe a systematic approach to minimally invasive valve-sparing aortic root reimplantation.
\end{abstract}

Keywords: Ministernotomy; valve-sparing; root aneurysm; tricuspid

Received: 27 July 2018; Accepted: 10 August 2018; Published: 13 August 2018.

doi: 10.21037 /jovs.2018.07.27

View this article at: http://dx.doi.org/10.21037/jovs.2018.07.27

\section{Introduction}

Valve-sparing aortic root reimplantation, originally described by David and furthered by El Khoury and colleagues, is an established technique in a patient with an aortic root aneurysm and normal aortic cusp morphology (1-6). Minimally invasive valve-sparing aortic root reimplantation is not routinely performed because of the steep learning curve associated with complex aortic root procedures (7). To address this learning curve, we report our standard technique for minimally invasive valvesparing aortic root reimplantation in a tricuspid aortic valve focusing on key technical points (Figure 1).

\section{Patient selection}

Patients ( $<65$ years of age) with normal aortic cusp morphology and aortic root aneurysms (diameter $>5 \mathrm{~cm}$ ) with or without aortic insufficiency are considered for minimally invasive valve-sparing aortic root reimplantation.

\section{Pre-operative preparation}

Echocardiography is used to assess the valve anatomy (bicuspid $v s$. tricuspid), severity of aortic insufficiency, presence of cusp calcification or prolapse and ventricular size and function. Contrast-enhanced computed tomography scan with 3 -dimensional reconstructions is useful to evaluate aortic root morphology and dimensions and whether the patient needs a concomitant ascending/ hemiarch replacement. Pulmonary function testing and conventional or computed tomography coronary angiography are performed in all patients.

\section{Equipment}

Important instruments include Vascular hooks, MIS needle holders, MIS forceps, Cor-Knot (LSI Solutions, Victor, NY, USA), Crochet hooks and Resano forceps.

\section{Procedure}

\section{Preoperative set-up}

The procedure is performed in supine position under general endotracheal anesthesia. Standard cardiac anesthesia monitoring is utilized with transesophageal echocardiography (TEE). External defibrillation pads are placed. Standard skin preparation and draping are performed. 


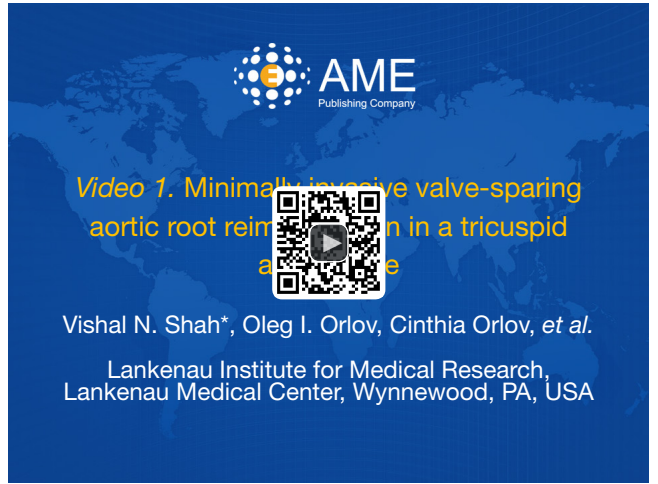

Figure 1 Minimally invasive valve-sparing aortic root reimplantation in a tricuspid aortic valve (8).

Available online: http://www.asvide.com/article/view/26343

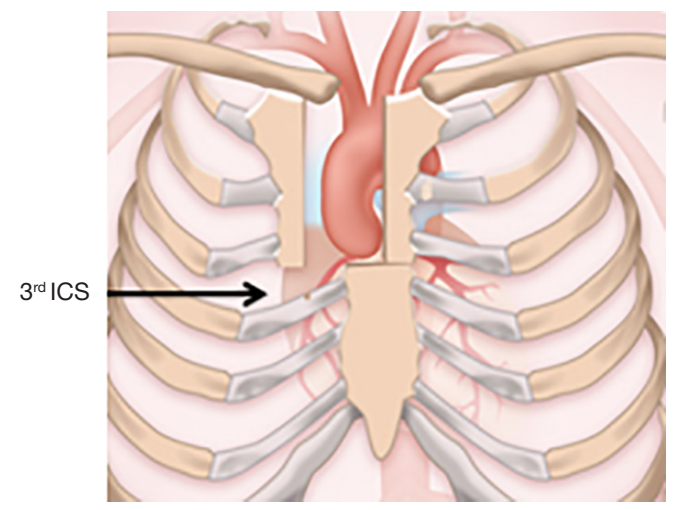

Figure 2 J-type ministernotomy incision extending to the right $3^{\text {rd }}$ or $4^{\text {th }}$ intercostal space. ICS, intercostal space.

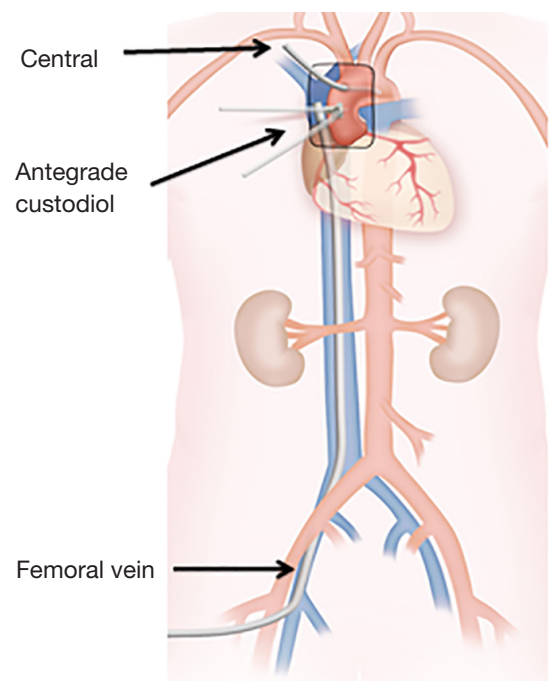

Figure 3 Cannulation and cardioplegia strategy.

\section{Incision}

A $6-\mathrm{cm}$ incision from $2-\mathrm{cm}$ inferior to the sternal notch to the midpoint of the third or fourth intercostal space is performed. We prefer a J-type ministernotomy exiting the right 3 rd or 4th intercostal space (Figure 2). The intercostal space on CT scan in the coronal view located adjacent to the aortic root is identified and the intercostal space above is entered. In case of a left-shifted aorta, a large aneurysm extending to the arch or reoperation, an inverted-T sternotomy is done.

\section{Cannulation}

Systemic heparin is administered. The aortic arch is directly cannulated using the Seldinger technique under TEE guidance (iE33 Philips Medical Systems, Andover, MA, USA). The right femoral vein is cannulated and a $25 \mathrm{~F}$ long femoral venous cannula (MC2, Medtronic, Dublin, Ireland) is subsequently advanced into the superior vena cava using the Seldinger technique under TEE guidance. We prefer to "Y" the femoral venous line to facilitate additional central venous drainage. Antegrade and retrograde autologous priming of the cardiopulmonary circuit is performed. After the aorta is cross-clamped, 2 liters of Custodiol-HTK cardioplegia (Essential Pharmaceuticals LLC, Ewing, NJ, USA) is given antegradely through the aortic root (Figure 3). We prefer Custodiol-HTK cardioplegia because it allows for up to one and half hours of myocardial protection in a single-dose. In cases of severe aortic insufficiency, an initial 1-liter dose of cardioplegia is administered and the remaining solution is then instilled directly into the coronary ostia. A direct pulmonary arterial vent is placed. After one and half hours of aortic crossclamp, an additional liter of cardioplegia is administered.

\section{Aortotomy and exposure}

The aorta is transected $1 \mathrm{~cm}$ above the sinotubular junction. Full-thickness 4-0 polypropylene traction sutures are placed at the level of the 3 commissures (Figure 4). The sutures are placed under tension and the annulus, cusps and sinuses of Valsalva are examined.

\section{Aortic root dissection}

The right and left coronary buttons are mobilized from inside the root. Root dissection starts along the 


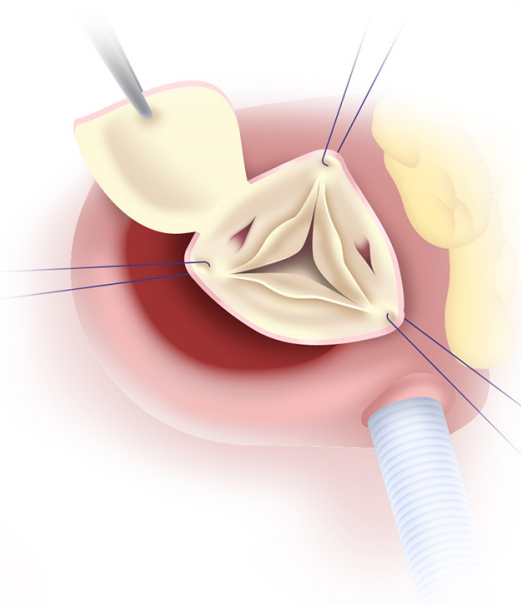

Figure 4 Traction sutures at the level of the 3 commissures.

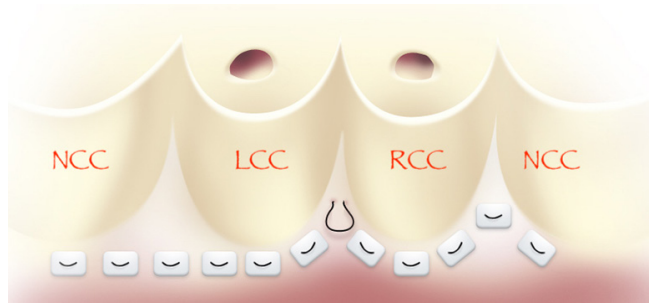

Figure 5 The proximal suture line is completed with pledget $\mathrm{U}$ stitches. Because the width of the interleaflet triangle at the RC/LC commissure is narrow, a non-pledgeted suture should be placed at this location. NCC, non-coronary commissure; LCC, left coronary commissure; RCC, right coronary commissure.

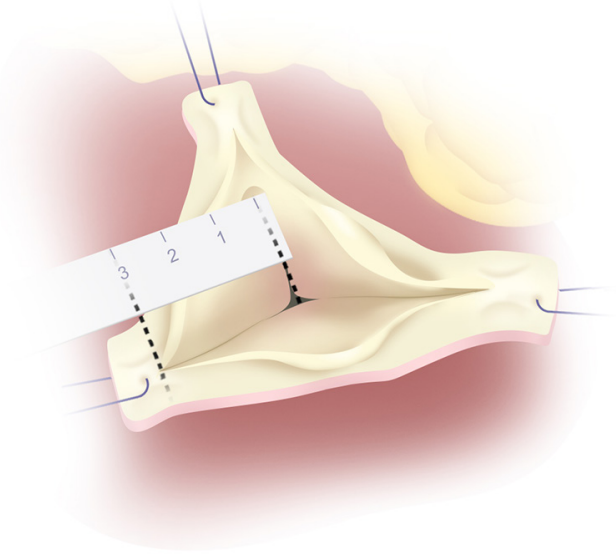

Figure 6 The height of the NC/LC commissure corresponds to the correct graft size. NC, non-coronary; LC, left coronary. non-coronary (NC) sinus and continues to the NC/left coronary (LC) commissure. The sinuses of Valsalva are excised, leaving $5 \mathrm{~mm}$ of the sinus wall attached. Dissection continues along the RC/LC commissure. In this area, dissection is restricted by the muscular septum. Dissection is continued along the RC sinus, where the right ventricular fibers are separated from the annulus. Dissection proceeds toward the NC/RC commissure. In this area, dissection is limited by the membranous septum (1-6). The aortic root is assessed and sized with a Hegar dilator or valve sizer. The ascending aorta is mobilized to the level of the aortic crossclamp.

\section{Proximal suture line}

Twelve 2-0 Ethibond sutures are passed through the annulus from beneath the aortic valve starting at the nadir of the NC sinus and proceeding clockwise. Subsequent sutures are placed in a horizontal line until the nadir of the LC sinus (Figure 5). Due to limitations of the external dissection at the $\mathrm{RC} / \mathrm{LC}$ and $\mathrm{NC} / \mathrm{RC}$ commissures, sutures are placed along the lowest portion of the root at these areas (1-6).

\section{Graft sizing and fixation and valve testing}

The 3 commissural sutures are pulled upwards to assess valve coaptation and to measure the height of the NC/LC commissure, which corresponds to the size of the Valsalva graft (Vascutek Ltd., a Terumo Company, Renfrewshire, Scotland) (Figure 6). The correct graft size can also be selected by measuring the sinotubular junction diameter when the commissural sutures are pulled up and adding $4 \mathrm{~mm}$. The top of the 3 commissures are placed $120^{\circ}$ degrees apart at the level of the neo-sinotubular junction, where the skirt of the Valsalva graft ends. Due to anatomic limitations of dissection at the RC/LC and NC/RC commissures, the proximal aspect of the graft must be trimmed accordingly at these locations. The excised portion of the proximal graft is equal to the size of the Valsalva graft minus the external height of the corresponding commissure.

Subvalvular annular sutures are passed through the aortic graft (Figure 7). The graft is then positioned and secured with use of Cor-Knot over a Hegar dilator placed within the aorto-ventricular junction. Generally, we use a 23-mm Hegar dilator for men and 21-mm Hegar dilator for women. The commissures are reimplanted at the appropriate height within the graft with 4-0 pledgeted polypropylene suture. The circumference of the aortic 


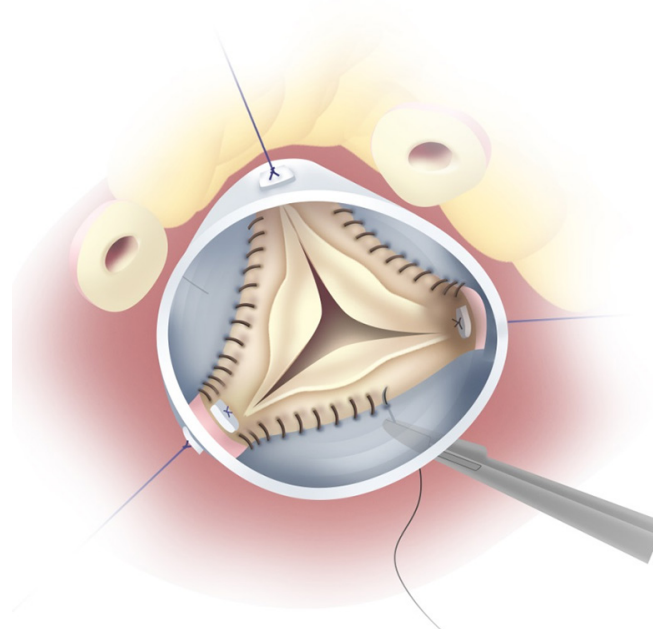

Figure 7 Subvalvular annular sutures are passed through the base of the aortic graft.

valve apparatus is then secured to the graft with running 4-0 polypropylene sutures. Schäfers caliper is used to measure the effective height of each commissure. The leaflet is prolapsed if the free edge is less than 8 or $9 \mathrm{~mm}$. Prolapse is repaired by free-end plication with $6-0$ polypropylene suture. After placing the aortic cusps in a closed position, the water test is used to determine competency of the valve.

\section{Coronaries reimplantation}

The left coronary button is reimplanted into the graft with Teflon-reinforced continuous full-thickness 5-0 polypropylene sutures. Cardioplegic solution is infused into the graft and left coronary artery to assess for hemostasis. The heart is filled and the appropriate location for the right coronary button is identified. The right coronary anastomosis is performed. Next, cardioplegia is administered to assess the integrity of the coronary anastomoses.

\section{Distal anastomosis}

The ascending aorta is divided approximately $1 \mathrm{~cm}$ proximal to the aortic cross-clamp. The prosthesis is cut to size and the distal anastomosis is performed with Teflon-strip reinforced continuous 4- 0 polypropylene suture. The posterior aspects of the distal anastomosis are reinforced with interrupted pledgeted 4-0 polypropylene suture. Prior to securing the distal anastomosis, de-airing maneuvers are performed. Epicardial pacing wires are placed with the heart decompressed. The aortic cross-clamp is removed and the distal anastomosis is secured. The patient is weaned from cardiopulmonary bypass. TEE is performed to assess for aortic insufficiency.

\section{Closure}

Our closure strategy includes rigid plate fixation (Zimmer Biomet, Warsaw, IN) and sternal wires typically with 2 plates and 2 wires. Two mediastinal drains (Ethicon, Inc., Somerville, NJ) and epicardial pacing wires are brought out the $3 \mathrm{rd}$ or 4 th intercostal space immediately lateral to the sternum.

\section{Role of team members}

The team should include the primary surgeon, first assistant, anesthesiologist, cardiologist, perfusionist and nurses. The primary surgeon orchestrates communication between all members. The anesthesiologist should be skilled in TEE in order to provide critical views including bi-caval, coronary sinus, long-axis aortic root and shortaxis of the descending aorta. Good communication with the cardiologist is necessary to provide postoperative monitoring and continued surveillance.

\section{Post-operative management}

Pacemaker wires can be removed on the $3 \mathrm{rd}$ or 4 th postoperative day in patients with no conduction disturbances. Chest tubes are removed for outputs less than $150 \mathrm{~mL}$ per day.

\section{Tips, tricks and pitfalls}

Minimally invasive operations are based on several fundamental tenets: optimal exposure, safe cannulation and cardioplegia strategies and use of facilitating technologies. Adjunctive techniques that improve exposure are placement of cephalad traction sutures around the aortic cross-clamp and through the edge of the pericardium. In patients with deep mediastinal structures, pericardial sutures are placed and tagged, the sternal retractor is removed, upward traction is then placed on the pericardial sutures and the sternal retractor is reinserted. Venous cannulation using the Seldinger technique under TEE guidance clears the operative field and provides excellent venous drainage. In cases of inadequate venous drainage, it is helpful to 
"Y" the venous line by inserting a second smaller cannula directly into the right atrium. Our cardioplegia strategy involves antegrade and retrograde autologous priming, minimizing the cardiopulmonary bypass circuit and routine ultrafiltration of excess crystalloid to avoid haemodilution. The Cor-Knot automated fastener and Custodiol-HTK cardioplegia are utilized in all minimally invasive operations by the senior author. We investigated the use of these two facilitating technologies in tandem in patients undergoing ministernotomy aortic valve and root replacements with good results $(9,10)$.

\section{Conclusions}

Our experience refers to a series of 13 patients who underwent minimally invasive valve-sparing aortic root reimplantation between 2016 and 2018. The average age was $51 \pm 10$ years and 12 patients $(92 \%)$ were males. There were $2(15 \%)$ redo procedures. Mean cardiopulmonary bypass time was $199 \pm 38$ minutes and mean cross-clamp time was $167 \pm 31$ minutes. Mortality, stroke, new-onset renal insufficiency and bleeding were $0 \%$. No patient required conversion to full sternotomy. Three (23\%) patients required prolonged ventilation ( $>48$ hours) and $3(23 \%)$ patients developed atrial fibrillation. Intensive care unit and hospital stays were $2.5 \pm 0.9$ and $5.8 \pm 1.9$ days respectively. To conclude, minimally invasive valve-sparing aortic root reimplantation can be performed safely and effectively by adhering to key technical principles.

\section{Acknowledgments}

Funding: None.

\section{Footnote}

Conflicts of Interest: All authors have completed the ICMJE uniform disclosure form (available at http://dx.doi. org/10.21037/jovs.2018.07.27). KAP serves as an unpaid editorial board member of Fournal of Visualized Surgery from Jun 2018 to May 2020. The other authors have no conflicts of interest to declare.

Ethical Statement: The authors are accountable for all aspects of the work in ensuring that questions related to the accuracy or integrity of any part of the work are appropriately investigated and resolved. All procedures performed in studies involving human participants were in accordance with the ethical standards of the institutional and/or national research committee(s) and with the Helsinki Declaration (as revised in 2013). Written informed consent was obtained from the patient for publication of this manuscript and video.

Open Access Statement: This is an Open Access article distributed in accordance with the Creative Commons Attribution-NonCommercial-NoDerivs 4.0 International License (CC BY-NC-ND 4.0), which permits the noncommercial replication and distribution of the article with the strict proviso that no changes or edits are made and the original work is properly cited (including links to both the formal publication through the relevant DOI and the license). See: https://creativecommons.org/licenses/by-nc-nd/4.0/.

\section{References}

1. David TE, Feindel CM. An aortic valve-sparing operation for patients with aortic incompetence and aneurysm of the ascending aorta. J Thorac Cardiovasc Surg 1992;103:61721; discussion 622 .

2. de Kerchove L, Mosala Nezhad Z, Boodhwani M, et al. How to perform valve sparing reimplantation in a tricuspid aortic valve. Ann Cardiothorac Surg 2013;2:105-12.

3. de Kerchove L, Jashari R, Boodhwani M, et al. Surgical anatomy of the aortic root: implication for valve-sparing reimplantation and aortic valve annuloplasty. J Thorac Cardiovasc Surg 2015;149:425-33. Erratum in: Notice of Correction [J Thorac Cardiovasc Surg 2016].

4. Boodhwani M, de Kerchove L, El Khoury G. Aortic root replacement using the reimplantation technique: tips and tricks. Interact Cardiovasc Thorac Surg 2009;8:584-6.

5. Jeanmart H, de Kerchove L, Glineur D, et al. Aortic valve repair: the functional approach to leaflet prolapse and valve-sparing surgery. Ann Thorac Surg 2007;83:S746-51; discussion S785-90.

6. de Kerchove L, Boodhwani M, Glineur D, et al. A new simple and objective method for graft sizing in valvesparing root replacement using the reimplantation technique. Ann Thorac Surg 2011;92:749-51.

7. Shrestha M, Krueger H, Umminger J, et al. Minimally invasive valve sparing aortic root replacement (David procedure) is safe. Ann Cardiothorac Surg 2015;4:148-53.

8. Shah VN, Orlov OI, Orlov C, et al. Minimally invasive valve-sparing aortic root reimplantation in a tricuspid aortic valve. Asvide 2018;5:671. Available online: http:// www.asvide.com/article/view/26343 
9. Plestis K, Orlov O, Shah VN, et al. Facilitating technologies in minimally invasive aortic valve replacement: a propensity score analysis. Interact Cardiovasc Thorac Surg 2018;27:202-7.

doi: 10.21037/jovs.2018.07.27

Cite this article as: Shah VN, Orlov OI, Orlov C, Sicouri S, Takebe M, Plestis KA. Minimally invasive valve-sparing aortic root reimplantation. J Vis Surg 2018;4:169.
10. Abjigitova D, Panagopoulos G, Orlov O, et al. Current Trends in Aortic Root Surgery: The Mini-Bentall Approach. Innovations (Phila) 2018;13:91-6. 